\title{
Mediterranean diet and Alzheimer disease mortality
}

\section{(6)}

Nikolaos Scarmeas, MD

Jose A. Luchsinger, MD

Richard Mayeux, MD Yaakov Stern, PhD

Address correspondence and reprint requests to Dr. N. Scarmeas, Columbia University Medical Center, 622 W. 168 St., PH 19th fl., New York, NY 10032 ns257@columbia.edu
Editorial, see page 1072

\section{ABSTRACT}

Background: We previously reported that the Mediterranean diet (MeDi) is related to lower risk for Alzheimer disease (AD). Whether MeDi is associated with subsequent AD course and outcomes has not been investigated.

Objectives: To examine the association between MeDi and mortality in patients with AD.

Methods: A total of 192 community-based individuals in New York who were diagnosed with AD were prospectively followed every 1.5 years. Adherence to the MeDi (0- to 9-point scale with higher scores indicating higher adherence) was the main predictor of mortality in Cox models that were adjusted for period of recruitment, age, gender, ethnicity, education, APOE genotype, caloric intake, smoking, and body mass index.

Results: Eighty-five patients with $A D(44 \%)$ died during the course of $4.4( \pm 3.6,0.2$ to 13.6 ) years of follow-up. In unadjusted models, higher adherence to MeDi was associated with lower mortality risk (for each additional MeDi point hazard ratio 0.79; 95\% Cl 0.69 to 0.91; $p=0.001$ ). This result remained significant after controlling for all covariates 10.76 ; 0.65 to $0.89 ; p=$ 0.001). In adjusted models, as compared with AD patients at the lowest MeDi adherence tertile, those at the middle tertile had lower mortality risk $(0.65 ; 0.38$ to $1.09 ; 1.33$ years' longer survival), whereas subjects at the highest tertile had an even lower risk (0.27; 0.10 to 0.69; 3.91 years' longer survival; $p$ for trend $=0.003$ ).

Conclusion: Adherence to the Mediterranean diet (MeDi) may affect not only risk for Alzheimer disease (AD) but also subsequent disease course: Higher adherence to the MeDi is associated with lower mortality in AD. The gradual reduction in mortality risk for higher MeDi adherence tertiles suggests a possible dose-response effect. Neurology ${ }^{\circledR}$ 2007;69:1084-1093

\section{GLOSSARY}

$\mathbf{A D}=$ Alzheimer disease; $\mathbf{B M I}=$ body mass index; $\mathbf{C D R}=$ Clinical Dementia Rating; HCFA = Health Care Finance Administration; $\mathbf{M e D i}=$ Mediterranean diet; WHICAP = Washington Heights and Inwood Columbia Aging Project.

Because dietary patterns analysis has the ability to integrate complex or subtle interactive effects of many dietary constituents and to capture the diet's multidimensionality, ${ }^{1}$ it has recently received growing attention in relation to many diseases (i.e., cirrhosis or various cancers). However, there is paucity of data regarding the effect of composite dietary patterns in the neurologic literature. One such dietary pattern is the Mediterranean diet (MeDi). The MeDi is characterized by high intake of vegetables, legumes, fruits, and cereals; high intake of unsaturated fatty acids (mostly in the form of olive oil), but low intake of saturated fatty acids; a moderately high intake of fish; a low-to-moderate intake of dairy products (mostly cheese or yogurt); a low intake of meat and poultry; and a regular but moderate amount of ethanol, primarily in the form of wine and generally

From the Taub Institute for Research in Alzheimer's Disease and the Aging Brain (N.S., J.A.L., R.M., Y.S.), Gertrude H. Sergievsky Center (N.S., R.M., Y.S.), and Departments of Neurology (N.S., R.M., Y.S.) and Medicine (J.A.L.), Columbia University Medical Center, New York.

Supported by federal NIA grants AG07232, AG07702, AG15294-06, 1K08AG20856-01, RR00645, the Charles S. Robertson Memorial Gift for Research in AD, the Blanchette Hooker Rockefeller Foundation, the New York City Council Speaker's Fund for Public Health Research, and the Taub Institute for Research on AD and the Aging Brain.

Disclosure: The authors report no conflicts of interest. 
MeDi = Mediterranean diet; $\mathrm{AD}=$ Alzheimer disease
Figure 1 Flow chart describing sample

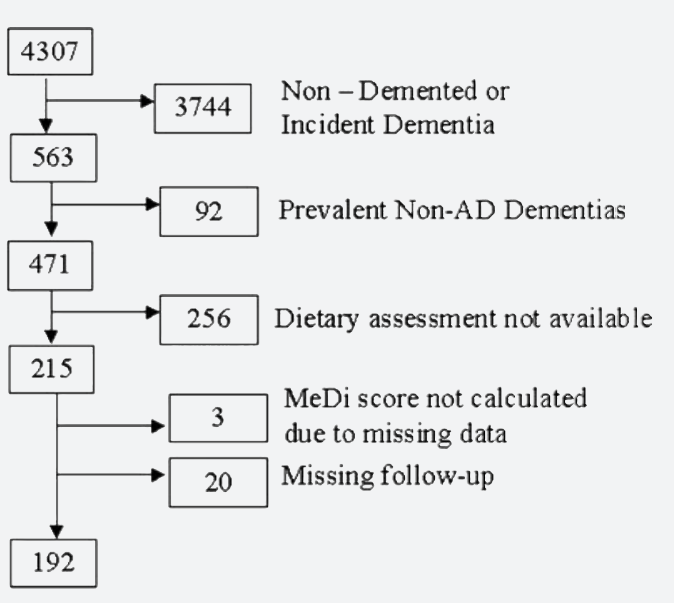

during meals. ${ }^{2}$ Hence, it seems to include many of the components reported as potentially beneficial for Alzheimer disease (AD) and cognitive performance.

We recently demonstrated that higher MeDi adherence is associated with lower AD risk. ${ }^{3,4}$ Whether MeDi adherence is associated with further AD course and prognosis has not been investigated. Because higher adherence to the MeDi has been associated with lower risk for a series of medical conditions and diseases including overall mortality in the general population, ${ }^{2,5,6}$ we hypothesized that it may be also associated with reduced mortality in AD populations too.

METHODS Sample and procedures. Data were included from individuals participating in a prospective study of aging and dementia in 4,307 Medicare recipients, age 65 and older, residing in northern Manhattan (Washington Heights, Hamilton Heights, Inwood; Washington Heights and Inwood Columbia Aging Project [WHICAP]). A stratified random sample of $50 \%$ of all persons older than 65 years was obtained from the Health Care Finance Administration (HCFA). ${ }^{3,4,7-10}$ All persons were sent a letter from HCFA explaining that they had been selected to participate in a study of aging by investigators at Columbia University. The sampling procedures have been described in detail elsewhere. ${ }^{3,47-10}$ Each participant underwent an in-person interview of general health and functional ability at the time of entry into the study followed by a standardized assessment, including medical history, physical and neurologic examination, and a neuropsychological battery. ${ }^{11}$ The neuropsychological battery contained tests of memory (short- and longterm verbal and nonverbal); orientation; abstract reasoning (verbal and nonverbal); language (naming, verbal fluency, comprehension, and repetition); and construction (copying and matching). Ethnic group was classified by participant's self-report using the format of the 1990 US Census. ${ }^{12}$ Partici- pants were asked if they considered themselves white, black, or other and then asked if they were Hispanic. According to their responses they were assigned to one of four groups: black (non-Hispanic), Hispanic, white (non-Hispanic), or other. Participants were recruited at two time points (1992 through 1994 and 1999 through 2002). They have been followed at approximately 18 -month intervals with similar assessments at each interval. Recruitment, informed consent, and study procedures were approved by the Institutional Review Boards of Columbia Presbyterian Medical Center and Columbia University Health Sciences and the New York State Psychiatric Institute.

A consensus diagnosis for the presence or absence of dementia was made at a diagnostic conference of neurologists and neuropsychologists where information of all the above evaluations was presented. Evidence of cognitive deficit (based on the neuropsychological scores as described above), evidence of impairment in social or occupational function (as assessed by the Blessed Dementia Rating Scale, the Schwab and England Activities of Daily Living Scale, and the physician's assessment), and evidence of cognitive and socialoccupational function decline as compared with the past were the criteria used for the diagnosis of dementia as required by the Diagnostic and Statistical Manual of Mental Disorders (rev. 3rd ed.). The type of dementia was subsequently determined. For the diagnosis of probable or possible $\mathrm{AD}$, the criteria of the National Institute of Neurological and Communicative Disorders and Stroke/Alzheimer's Disease and Related Disorders Association ${ }^{13}$ were used. Since in these criteria, stroke does not preclude the diagnosis of $\mathrm{AD}$ (unless cerebrovascular disease was considered the primary cause of the dementia), the diagnosis of AD with concomitant stroke was also assigned. A global summary score on the Clinical Dementia Rating (CDR) ${ }^{14}$ was also assigned. Dietary data were not available to the consensus panel and were not considered in the diagnostic process.

These analyses are restricted to subjects diagnosed with $\mathrm{AD}$ at the baseline WHICAP evaluation (prevalent AD patients) (figure 1). Among 471 subjects with prevalent AD, 256 were missing dietary assessments, leaving 215 with available dietary data. MeDi score could not be calculated for 3 and follow-up was not available for 20, leaving 192 subjects available for the final analyses.

Evaluation. Predictors. Diet. Dietary data regarding average food consumption over the last year were obtained using a 61-item Semiquantitative Food Frequency Questionnaire (SFFQ) (Channing Laboratory, Cambridge, MA). ${ }^{15}$ Trained interviewers administered the SFFQ in English (46\%) or Spanish $(53 \%)$. We have previously reported validity (using two 7-day food records) and reliability (using two 3-month frequency assessments) of various components of the SSFQ in WHICAP. ${ }^{7-9}$

Similarly to our previous work, ${ }^{3,4}$ we followed a method previously described ${ }^{2}$ for the construction of the MeDi score. More specifically, we first regressed caloric intake (kcal) and calculated the derived residuals of daily gram intake ${ }^{16}$ for each of the following seven categories ${ }^{2}$ : dairy, meat, fruits, vegetables, legumes, cereals, and fish. A value of 0 or 1 was assigned to each of the seven above groups, using sexspecific medians as cut-offs. For beneficial components (fruits, vegetables, legumes, cereals, and fish), persons whose consumption was below the median were assigned a value of 0 , and persons whose consumption was at or above the me- 
dian were assigned a value of 1 . For components presumed to be detrimental (meat and dairy products), persons whose consumption was below the median were assigned a value of 1 , and persons whose consumption was at or above the median were assigned a value of 0 . For fat intake (eighth food category), we used the ratio of daily consumption (in grams) of monounsaturated lipids to saturated lipids ${ }^{2}$ (again using sex-specific median cutoffs for assignment values of 0 for low and 1 for high). For alcohol intake (ninth food category), subjects were assigned a score of 0 for either no $(0 \mathrm{~g} /$ day $)$ or more than moderate ( $\geq 30 \mathrm{~g} /$ day) consumption and a value of 1 for mild to moderate alcohol consumption $(>0$ to $<30$ $\mathrm{g} /$ day). This is in agreement with previous reports ${ }^{2}$ that consider moderate amount of alcohol consumption as another characteristic component of the MeDi. We classified alcohol consumption dichotomously, also because of the skewed distribution of alcohol in our population $(68 \%$ reporting no alcohol intake, $31 \%$ reporting less than $30 \mathrm{~g} /$ day [mild to moderate intake], and $1 \%$ reporting $\geq 30 \mathrm{~g} /$ day [heavy intake]). The MeDi score was generated for each participant by adding the scores in the food categories (theoretically ranging from 0 to 9) with higher score indicating higher adherence to the MeDi.

In two previous publications, using a subset of subjects with repeated ${ }^{2-4}$ dietary assessments over a course of about 8 (and up to 13) years, we demonstrated that adherence to the MeDi is remarkably stable over time., Therefore, we considered that the MeDi adherence reported at baseline evaluation for our prevalent $\mathrm{AD}$ population reflects their dietary habits since clinical disease onset.

Covariates. Age (years), education (years), caloric intake ( $\mathrm{kcal}$ ), and body mass index (BMI; weight divided by height $\left.\left[\mathrm{kg} / \mathrm{m}^{2}\right]\right)^{17}$ were used as continuous variables. We also considered period of recruitment (1992 cohort as reference), gender (men as reference), and smoking status at baseline evaluation (no smoking as reference). Ethnic group was based on self-report using the format of the 1990 census. ${ }^{12}$ Ethnicity was used as a dummy variable with white (nonHispanic) as the reference. APOE genotype was used dichotomously: absence of $\varepsilon 4$ allele vs presence of either one or two $\varepsilon 4$ alleles.

Outcomes. Mortality was tracked through follow-up interviews every 18 months and through submission of identifying information for subjects reported to be dead or lost to follow-up to the National Death Index.

Statistical analyses. Characteristics of patients by mortality and by MeDi tertiles were compared using $t$ test or analysis of variance for continuous variables and $\chi^{2}$ test for categorical variables.

We calculated a basic Cox proportional hazards models with mortality as the dichotomous outcome. The time-toevent variable was time from baseline evaluation to death; persons who did not die were censored at the time of their last follow-up. MeDi score (from the baseline visit) was the main predictor (in a continuous form initially and in tertile form for trend test calculation subsequently). In subsequent Cox models we simultaneously adjusted for the following variables: period of recruitment, age at recruitment in the study, gender, ethnicity, education, APOE, smoking, caloric intake, and BMI.

We then constructed a series of supplementary models. Despite having demonstrated stability of adherence to the $\mathrm{MeDi}$, it is always possible that subjects' dietary habits are affected by progressing disease. It is also possible that dietary information collected from AD patients may be subject to decreased accuracy because of poor recall. To further explore the contribution of these factors to our results, we constructed four additional exploratory models. First, we repeated the above analyses excluding $\mathrm{AD}$ patients with CDR $>1(\mathrm{n}=18)$. Second, we included baseline cognitive performance (in the form of a composite standard $z$ score calculated using 12 neuropsychological tests from the administered battery ${ }^{11}$ [details previously published] $]^{4,18}$ ]) as a covariate. Third, we excluded a subset of subjects whose dietary assessment was more than 1 year after baseline cognitive assessment $(\mathrm{n}=34)$. Fourth, we recalculated the modes in a subset of incident $\mathrm{AD}$ patients (i.e., subjects who were nondemented when they were first included in the study and had their dietary evaluation and who developed AD during follow-up). In other supplementary analyses, we included only subjects who were diagnosed as having AD with stroke $(\mathrm{n}=61)$ using only $\mathrm{AD}$ without stroke as our population. In additional models we included as covariates baseline cardiovascular risk factors including diabetes, hypertension, and heart disease, as defined in our previous work. ${ }^{3}$ In brief, these covariates were defined by self-report or by the use of disease-specific medications and they have been shown to be reliable, sensitive, and specific in our study using medical records as the gold standard. ${ }^{3,19}$

RESULTS Missing data analyses. The main reason why patients with prevalent AD were missing dietary information was the fact that dietary assessment was not fully implemented since the beginning of the WHICAP but was added as a standard part of the evaluation after initiation of the study: 189 of 256 (74\%) subjects with missing dietary information were recruited in the $1992 \mathrm{co}-$ hort, but only 67 of 256 (26\%) in the 1999 cohort $(p<0.001)$. Mostly due to their earlier recruitment in the study, subjects with missing dietary information ( $\mathrm{n}=256$ ) compared with subjects with available dietary information $(n=215)$ had also higher mortality (70 vs 33\%; $p<0.001$ ). Additionally, they had lower baseline cognitive performance (composite $z$ score -1.33 vs -1.16 ; $p=$ 0.004 ), and they were less likely to be smokers (3 vs $8 \% ; p=0.01$ ) and hypertensive (55 vs $65 \%$; $p=0.05)$. There were no significant differences between subjects with missing and those with available dietary information in gender, age, ethnicity, education, APOE genotype, BMI, history of diabetes, or heart disease.

Given that the study is still ongoing, subjects with missing follow-up $(\mathrm{n}=20)$ as compared with subjects with available follow-up $(\mathrm{n}=192)$ were more likely to belong to the 1999 cohort (80 vs $56 \%$; $p=0.04)$. They were less likely to be whites and more likely to belong to other ethnicities (white 5\%, black 35\%, Hispanic 55\%, other $5 \%$ vs white $9 \%$, black $33 \%$, Hispanic $58 \%$, other $0 \% ; p=0.02$ ) and experienced less heart 


\begin{tabular}{|c|c|c|c|c|c|}
\hline \multirow[t]{2}{*}{ Table 1} & \multicolumn{5}{|c|}{$\begin{array}{l}\text { Demographic, clinical, and dietary characteristics for patients with Alzheimer disease who did and did } \\
\text { not die during follow-up }\end{array}$} \\
\hline & & Alive, $\mathrm{n}=107$ & Dead, $n=85$ & All, $n=192$ & $\mathrm{p}$ \\
\hline Age, $y$, me & SD) & $81.5(7.1)$ & $84.6(8.1)$ & $82.9(7.7)$ & 0.005 \\
\hline Gender, $\mathrm{m}$ & n (\%) & $23(21)$ & 19 (22) & $42(22)$ & 0.89 \\
\hline Education & mean (SD) & $5.5(4.4)$ & $6.5(4.8)$ & $5.9(4.6)$ & 0.08 \\
\hline \multicolumn{6}{|c|}{ Ethnicity, n (\%) } \\
\hline White & & 9 (8) & $9(11)$ & $18(9)$ & 0.11 \\
\hline Black & & $29(27)$ & $34(40)$ & 63 (33) & \\
\hline Hispanic & & $69(65)$ & $42(49)$ & $111(58)$ & \\
\hline Presence & 4 allele, n (\%) & 32 (37) & 20 (32) & 52 (35) & 0.57 \\
\hline Energy, kc & mean (SD) & 1468 (738) & 1463 (550) & $1466(660)$ & 0.95 \\
\hline Body mas & dex, mean (SD) & 27.1 (5.9) & $25.7(5.4)$ & 26.5 (5.7) & 0.11 \\
\hline Smoking, & & $10(9)$ & $7(8)$ & $17(9)$ & 0.79 \\
\hline MeDi scor & eean (SD) & $4.2(1.8)$ & $3.3(1.5)$ & $3.8(1.7)$ & $<0.001$ \\
\hline \multicolumn{6}{|c|}{ MeDi tertiles, $\mathrm{n}(\%)$} \\
\hline Low & & $43(40)$ & $49(58) 59$ & $92(48)$ & 0.008 \\
\hline Middle & & $41(38)$ & $30(35)$ & 71 (37) & \\
\hline High & & $23(22)$ & $6(7)$ & 29 (15) & \\
\hline Diabetes, & & $28(26)$ & $20(24)$ & $48(25)$ & 0.71 \\
\hline Hypertens & $n(\%)$ & $72(68)$ & $52(63)$ & $124(66)$ & 0.45 \\
\hline Heart dise & $\mathrm{n}(\%)$ & $21(20)$ & $25(30)$ & $46(24)$ & 0.11 \\
\hline Composit & gnition, mean (SD) & $-1.17(0.50)$ & $-1.17(0.57)$ & $-1.17(0.53)$ & 0.90 \\
\hline
\end{tabular}

$\mathrm{MeDi}=$ Mediterranean diet.

disease ( 5 vs $24 \%$; $p=0.05$ ). There were no significant differences between subjects with missing and those with available follow-up in gender, age, education, BMI, caloric intake, APOE genotype, baseline cognitive function, smoking status, history of diabetes, and hypertension. Most important, there was no difference in MeDi score (4.1 vs $3.8 ; p=0.37)$.

Clinical-demographic-dietary characteristics. Compared with AD patients who remained alive, AD patients who died did not differ in any clinical-demographic characteristic, with the exception of being older and having lower MeDi scores (table 1). There was no association between MeDi score and any clinical-demographic characteristic (table 2).

MeDi and mortality. AD patients were followed for 4.4 years (SD 3.6; range 0.2 to 13.6). Mean survival was 7.55 years (95\% CI 6.73 to 8.37 ). Higher adherence to the MeDi was associated with significantly lower mortality risk (table 3 and figure 2). The results were similar in adjusted and unadjusted models (table 3, models 1 and 2). Each additional unit of the MeDi score was associated with 21 to $24 \%$ lower risk of death. In unadjusted models, compared with $\mathrm{AD}$ patients in the lowest MeDi tertile (low adherence to the MeDi; mean survival 6.59 [5.53 to 7.66 ] years), AD patients in the middle MeDi score tertile had $29 \%$ lower risk of death (mean survival 7.92 [6.60 to 9.24] years), whereas those at the highest tertile (high adherence to the $\mathrm{MeDi}$ ) had $67 \%$ lower mortality risk (mean survival 10.50 [8.08 to 12.92] years), with a significant a trend for a doseresponse effect. Adjustment for all potential covariates made the associations even stronger: $35 \%$ less risk for the middle and $73 \%$ less mortality risk for the highest MeDi tertile.

Supplementary analyses. The majority of our subjects were of nonwhite ethnicity. Excluding the white subjects and repeating the analyses in black and Hispanic AD patients only did not change the associations (unadjusted models, HR $0.79 ; 0.67$ to $0.92 ; p=0.002$; tertile analyses $p$ for trend $=$ 0.01 ; adjusted models, HR $0.78 ; 0.66$ to $0.91 ; p=$ 0.002 ; tertile analyses $p$ for trend $=0.004$ ).

In models excluding $\mathrm{AD}$ patients with baseline CDR $>1$ (remaining in the analyses $n=174,73$ death events), higher adherence to the MeDi was associated with lower mortality risk in both unadjusted (HR 0.78; 0.67 to $0.91 ; p=0.001$; tertile analyses $p$ for trend $=0.02$ ) and adjusted models 


\begin{tabular}{|c|c|c|c|c|c|}
\hline \multirow[t]{2}{*}{ Table 2} & \multicolumn{5}{|c|}{$\begin{array}{l}\text { Demographic and clinical characteristics by Mediterranean diet (MeDi) score tertiles for all subjects } \\
\text { with Alzheimer disease }\end{array}$} \\
\hline & & $\begin{array}{l}\text { Low tertile } \\
\text { (MeDi score 0-3) }\end{array}$ & $\begin{array}{l}\text { Middle tertile } \\
\text { (MeDi score 4-5) }\end{array}$ & $\begin{array}{l}\text { High tertile } \\
\text { (MeDi score 6-9) }\end{array}$ & $p$ \\
\hline \multicolumn{2}{|c|}{ Cohort WHICAP 1999, n (\%) } & $48(52)$ & $38(54)$ & $21(72)$ & 0.14 \\
\hline \multicolumn{2}{|c|}{ Age, $y$, mean (SD) } & $83.2(7.8)$ & $83.5(7.1)$ & 80.1 (8.2) & 0.10 \\
\hline \multicolumn{2}{|c|}{ Gender, men, $n(\%)$} & $19(21)$ & $15(21)$ & $8(28)$ & 0.72 \\
\hline \multicolumn{2}{|c|}{ Education, y, mean (SD) } & $5.9(4.5)$ & $6.0(4.8)$ & $6.5(4.4)$ & 0.83 \\
\hline \multicolumn{6}{|c|}{ Ethnicity, $n(\%)$} \\
\hline \multicolumn{2}{|l|}{ White } & $8(44)$ & $8(44)$ & $2(11)$ & 0.50 \\
\hline \multicolumn{2}{|l|}{ Black } & $33(52)$ & $24(38)$ & $6(10)$ & \\
\hline \multicolumn{2}{|c|}{ Hispanic } & $51(46)$ & 39 (35) & $21(19)$ & \\
\hline \multicolumn{2}{|c|}{ Presence of $\varepsilon 4$ allele, $\mathrm{n}(\%)$} & $22(31)$ & $21(38)$ & $9(41)$ & 0.61 \\
\hline \multicolumn{2}{|c|}{ Energy, kcal, mean (SD) } & $1491(571)$ & $1370(481)$ & 1621 (1130) & 0.20 \\
\hline \multicolumn{2}{|c|}{ Body mass index, (SD) } & $26.9(5.9)$ & $25.8(4.6)$ & 26.8 (7.3) & 0.48 \\
\hline \multicolumn{2}{|c|}{ Smoking, n (\%) } & $9(10)$ & $7(10)$ & 1 (3) & 0.54 \\
\hline \multicolumn{2}{|c|}{ Diabetes, n (\%) } & $21(23)$ & $21(30)$ & $6(21)$ & 0.53 \\
\hline \multicolumn{2}{|c|}{ Hypertension, n (\%) } & $57(63)$ & $45(64)$ & $22(76)$ & 0.45 \\
\hline \multicolumn{2}{|c|}{ Heart disease, n (\%) } & $21(23)$ & $20(28)$ & $5(17)$ & 0.49 \\
\hline \multicolumn{2}{|c|}{ Composite cognition, mean (SD) } & $-1.21(0.51)$ & $-1.15(0.58)$ & $-1.10(0.45)$ & 0.53 \\
\hline
\end{tabular}

WHICAP $=$ Washington Heights and Inwood Columbia Aging Project

(HR 0.78 ; 0.66 to $0.92 ; p=0.003$; tertile analyses $p$ for trend $=0.013$ ).

Adding baseline cognitive performance as a covariate in the adjusted models did not change the associations (HR $0.78 ; 0.67$ to $0.92 ; p=0.003$; tertile analyses $p$ for trend $=0.005$ ).

When including only AD patients whose dietary assessment was performed not later than 1 year after the baseline cognitive assessment $(\mathrm{n}=$ 158, 74 death events), the associations between MeDi and mortality remained strong in both unadjusted (HR, 0.77 ; 0.66 to $0.90 ; p=0.001$; tertile analyses $p$ for trend $=0.01$ ) and adjusted analyses (HR, 0.73 ; 0.61 to $0.88 ; p=0.001$; tertile analyses $p$ for trend $=0.006$ ).

When the analyses were performed in a separate sample of incident AD patients $(\mathrm{n}=288,106$ death events), the associations between MeDi and mortality were again significant: adjusted analyses (HR, 0.83 ; 0.72 to 0.96 ; $p=0.014$; tertile analyses $p$ for trend $=0.022$ ).

When the models were run including only probable prevalent $\mathrm{AD}$ without stroke patients $(\mathrm{n}=131 ; 61$ death events), the associations were unchanged (HR, $0.72 ; 0.60$ to $0.86 ; p<0.001$; tertile analyses $p$ for trend $=0.005)$. Adjusted models produced even stronger associations $(\mathrm{OR}$, $0.62 ; 0.50$ to $0.76 ; p<0.001$; tertile analyses $p$ for trend $<0.001$ ).

Finally, in adjusted models additionally including terms for cardiovascular risk factors (diabetes, hypertension, heart disease), the associations between $\mathrm{MeDi}$ adherence and mortality were again unchanged $(\mathrm{HR}, 0.77 ; 0.65$ to

\begin{tabular}{|c|c|c|c|c|c|c|c|}
\hline Table 3 & \multicolumn{7}{|c|}{$\begin{array}{l}\text { Hazard ratios (HRs) for mortality by Mediterranean diet (MeDi) score either in continuous or in tertile } \\
\text { form. }\end{array}$} \\
\hline Model & All & Dead & $\begin{array}{l}\text { MeDi continuous } \\
\text { HR ( } 95 \% \mathrm{Cl})\end{array}$ & $p$ & & $\begin{array}{l}\text { MeDi tertiles } \\
\text { HR (95\%Cl) }\end{array}$ & $p$ for trend \\
\hline \multirow[t]{3}{*}{1} & 192 & 85 & $0.79(0.69-0.91)$ & 0.001 & Low & 1 (ref.) & 0.008 \\
\hline & & & & & Middle & $0.71(0.45-1.12)$ & \\
\hline & & & & & High & $0.33(0.13-0.83)$ & \\
\hline \multirow[t]{3}{*}{2} & 172 & 70 & $0.76(0.65-0.89)$ & 0.001 & Low & 1 (ref.) & 0.003 \\
\hline & & & & & Middle & $0.65(0.38-1.09)$ & \\
\hline & & & & & High & $0.27(0.10-0.69)$ & \\
\hline
\end{tabular}

Model 1 is unadjusted. Model 2 is adjusted for period of recruitment, age, gender, ethnicity, education, APOE genotype, caloric intake, smoking, and body mass index. 
Low tertile (score 0 to 3 ) corresponds to lower adherence to MeDi, middle tertile (score 4 to 5) to middle adherence, and high tertile (score 6 to 9) to higher adherence to MeDi. The figure is derived from a model that is adjusted for period of recruitment, age, gender, ethnicity, education, APOE genotype, caloric intake, smoking, and body mass index.
Figure 2 Survival curves based on Cox analyses comparing Alzheimer disease mortality in subjects belonging to each Mediterranean diet (MeDi) tertile ( $p$ for trend $=0.004$ )

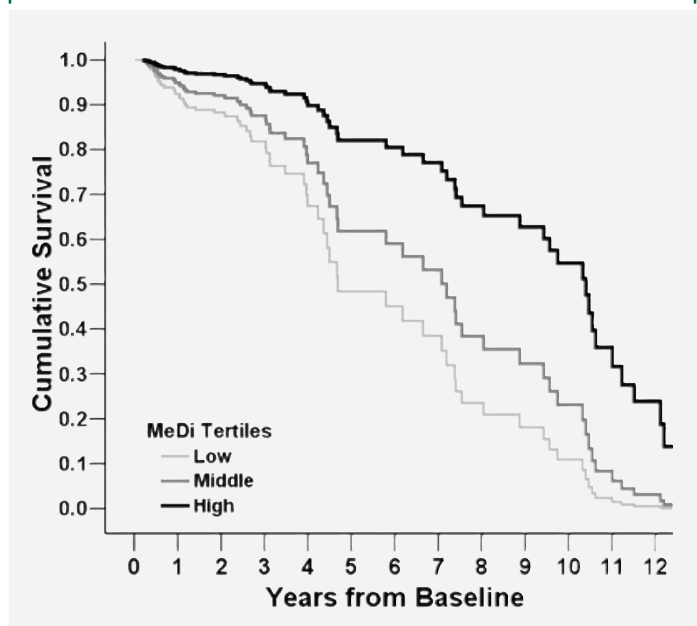

$0.91 ; p=0.002$; tertile analyses $p$ for trend $=$ $0.005)$.

DISCUSSION In our previous work we reported that higher adherence to the MeDi seems to reduce risk for getting AD. ${ }^{3,4}$ According to the current analyses, MeDi seems to affect subsequent $\mathrm{AD}$ course too. We found that higher adherence to the MeDi was associated with lower mortality in $\mathrm{AD}$. We noted a gradual reduction in mortality risk for higher MeDi adherence tertiles, which suggests a possible dose-response effect. The magnitude of the effect was considerable: As compared with subjects in the lowest MeDi adherence tertile, those in the medium MeDi adherence were 29 to $35 \%$ less likely to die, whereas those at the highest MeDi adherence tertile had a 67 to $73 \%$ reduction in mortality. Translating it into mean survival times, as compared with subjects in the lowest MeDi adherence tertile, those in the medium MeDi adherence lived 1.33 years longer, whereas those at the highest MeDi adherence tertile had a longer survival of 3.91 years.

Previous large general population studies indicated that the MeDi seems to protect from death from any cause. ${ }^{2,5,6}$ To our knowledge, no previous studies have investigated the effect of either dietary habits in general or of MeDi in particular regarding mortality risk in $\mathrm{AD}$ patients. In previous studies (either observational epidemiologic or interventional-clinical trials), higher adherence to the MeDi has been associated with reduced cardiac mortality 2,6,20,21 and reduced mortality from cancer. ${ }^{2}$ At the same time, medical comorbidities and in particular cardiovascular disease have been reported as predictors of mortality in dementia. ${ }^{22-26}$ We have not been able to investigate disease-specific mortality in this study. However, we attempted to partially address this issue by considering only subjects with probable AD (i.e., excluding $\mathrm{AD}$ patients with coexisting stroke) in the analyses and by adjusting for presence of baseline cardiovascular risk factors. The associations between MeDi and mortality remained unchanged.

The protection from mortality was present despite controlling for multiple other potential confounders. Weight loss in dementia and AD has been well documented. ${ }^{27-33} \mathrm{BMI}<23$ has been related to reduced 7-year survival of demented patients in one study. ${ }^{34}$ In another one, weight loss $>5 \%$ per year was a predictor of mortality among subjects with $\mathrm{AD}$, whereas weight gain appeared to have a protective effect..$^{27}$ In a prospective community study of patients with $\mathrm{AD}$, presence of cachexia was associated with increased mortality, ${ }^{35}$ and in another study malnutrition has been related to worse survival. ${ }^{26}$ In our study, there were no BMI differences for different MeDi adherence degrees. Additionally, the association between MeDi and AD mortality persisted despite controlling for BMI.

Older age has been associated with worse survival in multiple studies. ${ }^{25,26,36-44}$ Many studies have reported shorter survival for men with dementia as compared with women..$^{42,45-48}$ Regarding ethnic differences, the literature is mixed, with some studies finding higher mortality for Caucasians with $\mathrm{AD}^{26,49}$ and some others reporting no race differences..$^{36,39,50}$ Higher education has been associated with faster rates of cognitive decline ${ }^{18}$ and increased mortality ${ }^{38}$ in patients with AD. In our data we detected no association between MeDi adherence and either gender or ethnicity or education, while the associations with age were borderline nonsignificant. Most important, the association between MeDi and AD mortality persisted despite controlling for all the above characteristics.

The APOE genotype has been related to mortality in the general population, ${ }^{51-53}$ although this effect may vary for different ethnicities. ${ }^{51}$ In AD, the APOE genotype has been shown to relate to clinical $^{54-56}$ and physiologic ${ }^{57-59}$ heterogeneity, but its relation to mortality has been debatable. ${ }^{52,56,60,61}$ Because of the above, we considered the APOE genotype in our analyses, but we detected no differences in $\mathrm{MeDi}$ adherence between $\varepsilon 4$ carriers and noncarriers and no modification 
of the MeDi-mortality association when adjusting for $A P O E$ genotype.

Our study was conducted in a multiethnic urban cohort of New York City, which is unlikely to strictly consume foods typical of Mediterranean countries. Therefore, "true MeDi" adherence in our population may be significantly lower as compared with Mediterranean populations, and subjects with high $\mathrm{MeDi}$ adherence in New York may be potentially categorized as low MeDi adherence subjects if viewed in comparison with Mediterranean populations. This neither invalidates nor minimizes the significance of our finding because 1) transferability of the MeDi mortality advantages to other populations has been clearly demonstrated in multiple previous studies, ${ }^{6,62,63}$ and 2) there exists variability in MeDi adherence not only within our population but also within Mediterranean populations too. ${ }^{2}$ Therefore, the mortality risk for $\mathrm{AD}$ patients in New York with somehow higher MeDi adherence in comparison with AD patients in New York who are even further away from MeDi principles could be still lower. Given the known heterogeneity in diets across the globe, we fully realize that not all diets will fit the "true MeDi," but if we can identify those dietary habits that protect against AD mortality, we have made an important step in public health.

This study has limitations. The use of an a priori distribution-derived MeDi score assumes underlying monotonic effects, does not address possible thresholds or the shape of the underlying curve, and weighs equally the underlying individual food categories, which in turn are composed of different number of food constituents. Frequencies of food intake are based on relatively few diet constituents, which may underestimate the overall quantity of food in each food category, and a common limitation of studies of diet and disease is misclassification of exposure due to limited accuracy. However, assuming that the measurement error was random, our results may actually underestimate the association between high $\mathrm{MeDi}$ adherence and lower AD mortality.

Despite the use of standard criteria, the diagnostic expertise of our center, and the thorough workup, there is always the possibility of disease misclassification bias. ${ }^{64}$ As compared with subjects included in the current analyses, subjects with missing dietary information had higher mortality and lower baseline cognitive performance and were more likely nonsmokers and normotensive. Higher mortality for subjects without di- etary assessments reflects to a certain degree earlier recruitment in the study as dietary procedures were not implemented from the beginning of the 1992 cohort. However, we cannot completely exclude the possibility of bias due to attrition. Lower baseline cognitive performance may predispose to shorter survival, but nonsmoking status and normotension may predispose to longer one. Additionally, neither baseline cognition nor smoking status nor hypertension was associated with MeDi adherence in these patients with prevalent $\mathrm{AD}$ with available dietary assessments. We also included all these covariates in the adjusted models. Patients with $\mathrm{AD}$ with missing follow-up were few. They were mostly nonwhites with lower prevalence of heart disease. We detected no association between any of the above factors and MeDi adherence, and we considered all of them in the adjusted analyses. Overall, we cannot completely exclude (although it does not seem very likely) that our results could be explained by biases related to either missing dietary information or to loss from follow-up.

It is possible that diet is related to socioeconomic status or to other habits or characteristics related to better health and a lower risk for $\mathrm{AD}$ mortality. For the AD patients included in our study, MeDi was not related to vascular comorbidities, education, smoking, or ethnicity. We addressed this potential bias by also adjusting for all the above variables, but we cannot completely rule out residual confounding as an explanation for our findings.

It has been noted that dietary habits may change in AD. ${ }^{65-67}$ At the same time, better cognitive performance at baseline has been associated with longer AD survival. ${ }^{22-25,68-73}$ Therefore, another explanation for our findings is that differential adherence to the MeDi could be an indirect index of AD severity. A closely related issue is the potential inaccuracies in dietary reports by subjects with cognitive problems such as the patients with AD in this study. This may increase the overall dietary measurement error (which may actually bias the results toward the null), but there is no obvious reason to suggest that it may lead to misclassification bias (i.e., AD patients with longer future survival reporting "healthier" dietary habits). However, because we cannot completely exclude the above possibilities, we addressed them in several ways. First, we have previously reported stability in MeDi scores over intervals greater than 7 years for subjects with multiple dietary assessments who were not de- 
mented at baseline but developed AD during follow-up. ${ }^{3,4}$ Additionally, we have reported similar stability for MeDi adherence even for subjects without dementia. ${ }^{4}$ Second, when excluding subjects whose dietary assessments took place long after baseline cognitive assessment-diagnosis, the associations between $\mathrm{MeDi}$ and mortality were unchanged. Third, MeDi adherence was not related to baseline cognitive performance in this population. Fourth, when we adjusted for baseline cognitive performance, the associations were unchanged. Fifth, when we included in our analyses only patients at the early stages of AD (CDR not greater than 1), the associations were again unchanged. Sixth, the associations between $\mathrm{MeDi}$ and mortality were present in a separate sample of $\mathrm{AD}$ patients, for whom the dietary questionnaire was administered years before clinical AD incidence, when they were cognitively nondemented.

The noted associations between MeDi and mortality are based on relatively small sample sizes, including small number of death events and relatively short follow-up. Although we replicated the associations in a separate sample of incident AD patients, independent confirmation of our findings in other studies is necessary. It should be also noted that the vast majority of our population is Hispanics and blacks and inferences regarding similar effects in whites may be limited.

Last, we could not account for possible differences in end-of-life care, such as the use of artificial feeding or antibiotic therapy. However, despite some reports suggesting possible protective effect for such interventions,${ }^{74}$ their effectiveness has been questioned by multiple studies. ${ }^{74-76}$ Additionally there is no obvious reason to suggest that differential MeDi adherence would be related to differential utilization of such end-of-life measures.

Confidence in our findings is strengthened by the following factors. Dietary data were collected with a previously validated and used widely in epidemiologic studies instrument. ${ }^{15}$ We used an a priori developed dietary pattern. ${ }^{1,2}$ Measures for multiple potential mortality risk factors have been carefully recorded and adjusted for in the analyses. The diagnosis of AD took place in a university hospital with expertise in dementia and was based on comprehensive assessment and standard research criteria. The study is community based, and the population is multiethnic.

Received November 21, 2006. Accepted in final form April 9, 2007.

\section{REFERENCES}

1. Jacques PF, Tucker KL. Are dietary patterns useful for understanding the role of diet in chronic disease? Am J Clin Nutr 2001;73:1-2.

2. Trichopoulou A, Costacou T, Bamia C, Trichopoulos D. Adherence to a Mediterranean diet and survival in a Greek population. N Engl J Med 2003;348:2599-2608.

3. Scarmeas N, Stern Y, Mayeux R, Luchsinger JA. Mediterranean diet, Alzheimer disease, and vascular mediation. Arch Neurol 2006;63:1709-1717.

4. Scarmeas N, Stern Y, Tang MX, Mayeux R, Luchsinger JA. Mediterranean diet and risk for Alzheimer's disease. Ann Neurol 2006;59:912-921.

5. Trichopoulou A, Orfanos P, Norat T et al. Modified Mediterranean diet and survival: EPIC-elderly prospective cohort study. Br Med J 2005;330:991.

6. Knoops KT, de Groot LC, Kromhout D, et al. Mediterranean diet, lifestyle factors, and 10-year mortality in elderly European men and women: the HALE project. JAMA 2004;292:1433-1439.

7. Luchsinger JA, Tang MX, Shea S, Mayeux R. Caloric intake and the risk of Alzheimer disease. Arch Neurol 2002;59:1258-1263.

8. Luchsinger JA, Tang MX, Shea S, Mayeux R. Antioxidant vitamin intake and risk of Alzheimer disease. Arch Neurol 2003;60:203-208.

9. Luchsinger JA, Tang MX, Siddiqui M, Shea S, Mayeux R. Alcohol intake and risk of dementia. J Am Geriatr Soc 2004;52:540-546.

10. Scarmeas N, Levy G, Tang MX, Manly J, Stern Y. Influence of leisure activity on the incidence of Alzheimer's disease. Neurology 2001;57:2236-2242.

11. Stern Y, Andrews H, Pittman J, et al. Diagnosis of dementia in a heterogeneous population. Development of a neuropsychological paradigm-based diagnosis of dementia and quantified correction for the effects of education. Arch Neurol 1992;49:453-460.

12. Census of Population and Housing. Summary tape file1, technical documentation. Washington, DC: Bureau of the Census, 1991.

13. McKhann G, Drachman D, Folstein M, Katzman R, Price D, Stadlan EM. Clinical diagnosis of Alzheimer's disease: report of the NINCDS-ADRDA Work Group under the auspices of Department of Health and Human Services Task Force on Alzheimer's Disease. Neurology 1984;34:939-944.

14. Hughes CP, Berg L, Danziger WL, Coben LA, Martin RL. A new clinical scale for the staging of dementia. Br J Psychiatry 1982;140:566-572.

15. Willett WC, Sampson L, Stampfer MJ, et al. Reproducibility and validity of a semiquantitative food frequency questionnaire. Am J Epidemiol 1985;122:5165.

16. Willett W, Stampfer M. Implications of total energy intake for epidemiological analyses. In: Willett W, ed. Nutritional epidemiology. New York: Oxford University Press, 1998:122:273-301.

17. Kuczmarski R, Carroll M, Flegal K, Troiano R. Varying body mass index cutoff points to describe overweight prevalence among U.S. adults: NHANES III (1988 to 1994). Obes Res 1997;5:542-548.

18. Scarmeas N, Albert SM, Manly JJ, Stern Y. Education and rates of cognitive decline in incident Alzheimer's 
disease. J Neurol Neurosurg Psychiatry 2006;77:308316.

19. Luchsinger JA, Tang MX, Shea S, Mayeux R. Hyperinsulinemia and risk of Alzheimer disease. Neurology 2004;63:1187-1192.

20. de Lorgeril M, Salen P, Martin JL, Monjaud I, Delaye J, Mamelle N. Mediterranean diet, traditional risk factors, and the rate of cardiovascular complications after myocardial infarction: final report of the Lyon Diet Heart Study. Circulation 1999;99:779-785.

21. Singh RB, Dubnov G, Niaz MA, et al. Effect of an Indo-Mediterranean diet on progression of coronary artery disease in high risk patients (IndoMediterranean Diet Heart Study): a randomised singleblind trial. Lancet 2002;360:1455-1461.

22. Burns A, Lewis G, Jacoby R, Levy R. Factors affecting survival in Alzheimer's disease. Psychol Med 1991;21: 363-370.

23. Moritz DJ, Fox PJ, Luscombe FA, Kraemer HC. Neurological and psychiatric predictors of mortality in patients with Alzheimer disease in California. Arch Neurol 1997;54:878-885.

24. Larson EB, Shadlen MF, Wang L, et al. Survival after initial diagnosis of Alzheimer disease. Ann Intern Med 2004;140:501-509.

25. Scarmeas N, Albert M, Brandt J, et al. Motor signs predict poor outcomes in Alzheimer disease. Neurology 2005;64:1696-1703.

26. Gambassi G, Landi F, Lapane KL, Sgadari A, Mor V, Bernabei R. Predictors of mortality in patients with Alzheimer's disease living in nursing homes. J Neurol Neurosurg Psychiatry 1999;67:59-65.

27. White H, Pieper C, Schmader K. The association of weight change in Alzheimer's disease with severity of disease and mortality: a longitudinal analysis. J Am Geriatr Soc 1998;46:1223-1227.

28. Nielsen H, Lolk A, Pedersen I, Autzen M, Sennef C, Kragh-Sorensen P. The accuracy of early diagnosis and predictors of death in Alzheimer's disease and vascular dementia - a follow-up study. Acta Psychiatr Scand 1991;84:277-282.

29. Wang SY, Fukagawa N, Hossain M, Ooi WL. Longitudinal weight changes, length of survival, and energy requirements of long-term care residents with dementia. J Am Geriatr Soc 1997;45:1189-1195.

30. Cronin-Stubbs D, Beckett LA, Scherr PA, et al. Weight loss in people with Alzheimer's disease: a prospective population based analysis. Br Med J 1997;314:178-179.

31. White H. Weight change in Alzheimer's disease. J Nutr Health Aging 1998;2:110-112.

32. Wolf-Klein GP, Silverstone FA. Weight loss in Alzheimer's disease: an international review of the literature. Int Psychogeriatr 1994;6:135-142.

33. Shatenstein B, Kergoat MJ, Nadon S. Weight change, nutritional risk and its determinants among cognitively intact and demented elderly Canadians. Can J Public Health 2001;92:143-149.

34. Faxen-Irving G, Basun H, Cederholm T. Nutritional and cognitive relationships and long-term mortality in patients with various dementia disorders. Age Ageing 2005;34:136-141.

35. Evans DA, Smith LA, Scherr PA, Albert MS, Funkenstein $\mathrm{HH}$, Hebert LE. Risk of death from Alzheimer's disease in a community population of older persons. Am J Epidemiol 1991;134:403-412.

36. Hier DB, Warach JD, Gorelick PB, Thomas J. Predictors of survival in clinically diagnosed Alzheimer's disease and multi-infarct dementia. Arch Neurol 1989;46: 1213-1216.

37. Volicer BJ, Hurley A, Fabiszewski KJ, Montgomery P, Volicer L. Predicting short-term survival for patients with advanced Alzheimer's disease. J Am Geriatr Soc 1993;41:535-540.

38. Stern Y, Tang MX, Denaro J, Mayeux R. Increased risk of mortality in Alzheimer's disease patients with more advanced educational and occupational attainment. Ann Neurol 1995;37:590-595.

39. Heyman A, Peterson B, Fillenbaum G, Pieper C. The consortium to establish a registry for Alzheimer's disease (CERAD). Part XIV: demographic and clinical predictors of survival in patients with Alzheimer's disease. Neurology 1996;46:656-660.

40. Reisberg B, Ferris SH, Franssen EH, et al. Mortality and temporal course of probable Alzheimer's disease: a 5-year prospective study. Int Psychogeriatr 1996;8:291311.

41. Aguero-Torres H, Fratiglioni L, Guo Z, Viitanen M, Winblad B. Prognostic factors in very old demented adults: a seven-year follow-up from a populationbased survey in Stockholm. J Am Geriatr Soc 1998;46: 444-452.

42. Brookmeyer R, Corrada MM, Curriero FC, Kawas C. Survival following a diagnosis of Alzheimer disease. Arch Neurol 2002;59:1764-1767.

43. Helmer C, Joly P, Letenneur L, Commenges D, Dartigues JF. Mortality with dementia: results from a French prospective community-based cohort. Am J Epidemiol 2001;154:642-648.

44. Wolfson C, Wolfson DB, Asgharian M, et al. A reevaluation of the duration of survival after the onset of dementia. N Engl J Med 2001;344:1111-1116.

45. van Dijk PT, van de Sande HJ, Dippel DW, Habbema JD. The nature of excess mortality in nursing home patients with dementia. J Gerontol 1992;47:M28-M34.

46. Jagger C, Clarke M, Stone A. Predictors of survival with Alzheimer's disease: a community-based study. Psychol Med 1995;25:171-177.

47. Stern Y, Tang MX, Albert MS, et al. Predicting time to nursing home care and death in individuals with Alzheimer disease. JAMA 1997;277:806-812.

48. Geerlings MI, Deeg DJ, Schmand B, Lindeboom J, Jonker C. Increased risk of mortality in Alzheimer's disease patients with higher education? A replication study. Neurology 1997;49:798-802.

49. Chandra V, Bharucha NE, Schoenberg BS. Patterns of mortality from types of dementia in the United States, 1971 and 1973-1978. Neurology 1986;36:204-208.

50. Waring SC, Doody RS, Pavlik VN, Massman PJ, Chan W. Survival among patients with dementia from a large multi-ethnic population. Alzheimer Dis 2005;19:178183.

51. Lee JH, Tang MX, Schupf N, et al. Mortality and apolipoprotein E in Hispanic, African-American, and Caucasian elders. Am J Med Genet 2001;103:121-127.

52. Honig LS, Schupf N, Lee JH, Tang MX, Mayeux R. Shorter telomeres are associated with mortality in 
those with APOE epsilon4 and dementia. Ann Neurol 2006;60:181-187.

53. Schachter F, Faure-Delanef L, Guenot F, et al. Genetic associations with human longevity at the APOE and ACE loci. Nat Genet 1994;6:29-32.

54. Scarmeas N, Brandt J, Albert M, et al. Association between the APOE genotype and psychopathologic symptoms in Alzheimer's disease. Neurology 2002;58: 1182-1188.

55. Scarmeas N, Hadjigeorgiou GM, Papadimitriou A, et al. Motor signs during the course of Alzheimer disease. Neurology 2004;63:975-982.

56. Stern Y, Brandt J, Albert M, et al. The absence of an apolipoprotein epsilon 4 allele is associated with a more aggressive form of Alzheimer's disease. Ann Neurol 1997;41:615-620.

57. Scarmeas N, Anderson KE, Hilton J, et al. APOEdependent PET patterns of brain activation in Alzheimer disease. Neurology 2004;63:913-915.

58. Scarmeas N, Habeck C, Anderson KE, et al. Altered PET functional brain responses in cognitively intact elderly persons at risk for Alzheimer disease (carriers of the \{epsilon\} 4 allele). Am J Geriatr Psychiatry 2004;12: 596-605.

59. Scarmeas N, Stern Y. Imaging studies and APOE genotype in persons at risk for Alzheimer's disease. Curr Psychiatry Rep 2006;8:11-17.

60. Dal Forno G, Carson KA, Brookmeyer R, Troncoso J, Kawas $\mathrm{CH}$, Brandt J. APOE genotype and survival in men and women with Alzheimer's disease. Neurology 2002;58:1045-1050.

61. Koivisto AM, Lempiainen P, Koivisto K, et al. Apolipoprotein $\mathrm{E}$ phenotype alone does not influence survival in Alzheimer's disease: a population-based longitudinal study. Neuroepidemiology 2000;19:327332.

62. Kouris-Blazos A, Gnardellis C, Wahlqvist ML, Trichopoulos D, Lukito W, Trichopoulou A. Are the advantages of the Mediterranean diet transferable to other populations? A cohort study in Melbourne, Australia. Br J Nutr 1999;82:57-61.

63. Trichopoulou A, Orfanos P, Norat T, et al. Modified Mediterranean diet and survival: EPIC-elderly prospective cohort study. Br Med J 2005;330:991.

64. Knopman DS, DeKosky ST, Cummings JL, et al. Practice parameter: diagnosis of dementia (an evidence- based review). Report of the Quality Standards Subcommittee of the American Academy of Neurology. Neurology 2001;56:1143-1153.

65. Morris CH, Hope RA, Fairburn CG. Eating habits in dementia. A descriptive study. Br J Psychiatry 1989; 154:801-806.

66. Cooper JK, Mungas D. Serotonin response in sweetfood craving Alzheimer's disease subjects. Aging (Milano) 1992;4:165-169.

67. Mungas D, Cooper JK, Weiler PG, Gietzen D, Franzi C, Bernick C. Dietary preference for sweet foods in patients with dementia. J Am Geriatr Soc 1990;38:9991007.

68. Bianchetti A, Scuratti A, Zanetti O, et al. Predictors of mortality and institutionalization in Alzheimer disease patients 1 year after discharge from an Alzheimer dementia unit. Dementia 1995;6:108-112.

69. Molsa PK, Marttila RJ, Rinne UK. Long-term survival and predictors of mortality in Alzheimer's disease and multi-infarct dementia. Acta Neurol Scand 1995;91: 159-164.

70. Claus JJ, van Gool WA, Teunisse S, et al. Predicting survival in patients with early Alzheimer's disease. Dement Geriatr Cogn Disord 1998;9:284-293.

71. Schaufele M, Bickel H, Weyerer S. Predictors of mortality among demented elderly in primary care. Int J Geriatr Psychiatry 1999;14:946-956.

72. Drachman DA, O’Donnell BF, Lew RA, Swearer JM. The prognosis in Alzheimer's disease. "How far" rather than "how fast" best predicts the course. Arch Neurol 1990;47:851-856.

73. Kraemer HC, Tinklenberg J, Yesavage JA. "How far" vs "how fast" in Alzheimer's disease. The question revisited. Arch Neurol 1994;51:275-279.

74. Fabiszewski KJ, Volicer B, Volicer L. Effect of antibiotic treatment on outcome of fevers in institutionalized Alzheimer patients. JAMA 1990;263:3168-3172.

75. Finucane TE, Christmas C, Travis K. Tube feeding in patients with advanced dementia: a review of the evidence. JAMA 1999;282:1365-1370.

76. Meier DE, Ahronheim JC, Morris J, Baskin-Lyons S, Morrison RS. High short-term mortality in hospitalized patients with advanced dementia: lack of benefit of tube feeding. Arch Intern Med 2001;161:594-599. 


\section{Neurology}

Mediterranean diet and Alzheimer disease mortality

Nikolaos Scarmeas, Jose A. Luchsinger, Richard Mayeux, et al.

Neurology 2007;69;1084-1093

DOI 10.1212/01.wnl.0000277320.50685.7c

This information is current as of September 10, 2007

Updated Information \& Services

Supplementary Material

References

Citations

Subspecialty Collections

Permissions \& Licensing

Reprints including high resolution figures, can be found at:

http://www.neurology.org/content/69/11/1084.full.html

Supplementary material can be found at: http://www.neurology.org/content/suppl/2008/09/04/69.11.1084.DC1

This article cites 74 articles, 25 of which you can access for free at: http://www.neurology.org/content/69/11/1084.full.html\#\#ref-list-1

This article has been cited by 11 HighWire-hosted articles: http://www.neurology.org/content/69/11/1084.full.html\#\#otherarticles

This article, along with others on similar topics, appears in the following collection(s):

\section{Alzheimer's disease}

http://www.neurology.org//cgi/collection/alzheimers_disease

Cohort studies

http://www.neurology.org//cgi/collection/cohort_studies

Incidence studies

http://www.neurology.org//cgi/collection/incidence_studies

Risk factors in epidemiology

http://www.neurology.org//cgi/collection/risk_factors_in_epidemiology

Information about reproducing this article in parts (figures,tables) or in its entirety can be found online at:

http://www.neurology.org/misc/about.xhtml\#permissions

Information about ordering reprints can be found online:

http://www.neurology.org/misc/addir.xhtml\#reprintsus

Neurology ${ }^{\circledR}$ is the official journal of the American Academy of Neurology. Published continuously since 1951, it is now a weekly with 48 issues per year. Copyright . All rights reserved. Print ISSN: 0028-3878. Online ISSN: 1526-632X.

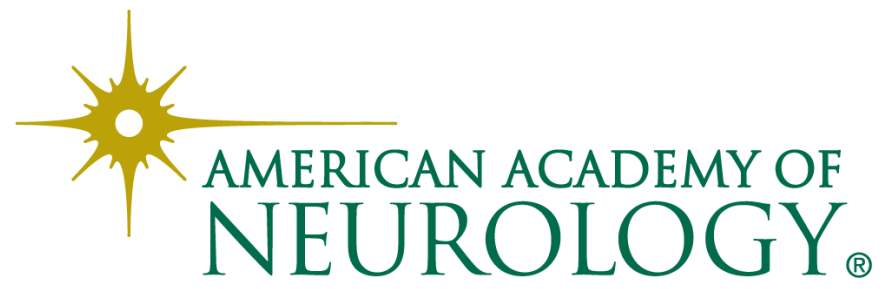

